\title{
Management of Hepatotoxicity in HIV-Infected Patients Treated with Combined Antiretroviral Therapy (cART): A Retrospective Cohort Study in Tianjin, China
}

Ping Ma ${ }^{1,3 \#}$, Jing Qian" ${ }^{1 \#}$ Liying Gao ${ }^{1}$, Defa Zhang ${ }^{1}$, Aiping $\mathrm{Yu}^{1}$, Chunting Qiu${ }^{1}$ and Min Wei ${ }^{2 *}$

${ }^{1}$ The Tianjin Second People's Hospital, Tianjin, China

${ }^{2}$ School of Medicine, Nankai University, Tianjin, China

${ }^{3}$ Tianjin Institute of Liver Disease, Tianjin, China

\#Authors contributed equally

\begin{abstract}
Background: Liver diseases are among the most frequent causes of non-AIDS-related deaths in human immunodeficiency virus (HIV)-infected patients due to hepatitis B or C virus co-infections, and/or the toxicity of longterm treatment of some antiviral drugs. There are few cohort studies reported in China.

Methods: All data from the clinic HIVIAIDS patients in the database of Tianjin Second People's Hospital, a branch of the National Free Antiretroviral Treatment Program database, from April 1, 2010 to March 31, 2016 were retrospectively assessed and analyzed.

Results: We analyzed 2270 HIV-positive, hepatitis B virus (HBV-), hepatitis C virus (HCV-) negative patients, who received cART and followed for 13334.8 person-years. A total of 67 patients (3.0\%, or 5.0 per 1000 person-years) died of non-liver-related causes. The incidence of liver-related deaths in persons without HCV or HBV co-infections was zero percent during follow-up. Only 30 cases $(1.3 \%$ or 2.2 per 1000 person-years) developed hepatotoxicity, but liver function of these patients improved after changing CART regimens.
\end{abstract}

Conclusion: CART-related hepatotoxicity can be well-controlled and managed by modifying the therapeutic regimens. Liver-related mortality in HIV-positive, HBV-, HCV-negative patients is currently zero percent in Tianjin, China.

Keywords: Hepatotoxicity; Combined antiretroviral therapy; HIV infection; Cohort study

Abbreviations: HIV: Human Immunodeficiency Virus; HBV: Hepatitis B Virus; HCV: Hepatitis C Virus; LEE: Liver Enzyme Elevation; MSM; Men who have Sex with Men; ALT: Alanine Transaminase; AST: Aspartate Transaminase; TBIL: Total Bilirubin; EFV: Efavirenz; 3TC: Lamivudine; AZT: Zidovudine; D4T: Stavudine; NVP: Nevirapine; TDF: Tenofovir

\section{Introduction}

China experienced sporadic reports in 1980s of HIV/AIDS epidemic. An outbreak in intravenous drug users (IDUs) in Yunnan province was reported in 1989 [1]. In the mid-1990s, another outbreak was reported among blood donors in central China, in the Henan and Anhui provinces. Since the late of 1990s and the early of 2000s, HIV infection has grown rapidly and has spread through out all of China $[1,2]$. HIV transmission also gradually shifted from intravenousdrug use to homosexual or heterosexual contact. In recent years, the prevalence of HIV infection in men who have sex with men (MSM) is rapidly increasing in the largest cities, such as Beijing, Shanghai and Tianjin [1-4]. Tianjin city is a large city, one of the four cities governed directly by central government in China. Tianjin, facing Bohai Gulf, is the eastern door of capital Beijing. All of the HIV/AIDS patients in Tianjin were treated and followed in our hospital, The Tianjin Second Peoples' Hospital (former Tianjin Infectious Disease Hospital). All of HIV-positive cases found in other hospitals in Tianjin and nearby areas were transferred to our hospital. This study will report the Tianjin's HIV/AIDS cohort.

In 2003, the Chinese government launched the China National Free Antiretroviral Therapy Program, which continues to offer anti-retroviral agents free of charge to Chinese HIV/AIDS patients [3,4]. This program makes it easier for these patients to receive modern combined antiretroviral therapy (cART). The cART has been shown to significantly reduce the mortality of HIV/AIDS, transforming a once fatal disease into one that is more aptly described as chronic, but manageable disease. This progress, however, comes with new challenges. Side effects of cART have emerged as a major issue for HIV/AIDS treatment, and the management of anti-retroviral toxicity becomes a key focus in patient care. One of the side effects of antiretroviral agents is hepatotoxicity $[5,6]$. On the other hand, hepatitis virus co-infection, the great concern in Chinese HIV/AIDS infected patients, even worsen the effects of hepatotoxicity and further complicate the clinical management. The Data Collection on Adverse Events of Anti-HIV Drug (D:A:D) cohort study and the Euro SIDA observational cohort study showed that liver diseases are among the most frequent causes of non-AIDS-related deaths in HIV-positive patients [711]. Many deaths were related to hepatitis $B$ virus (HBV-) or hepatitis $C$ virus (HCV-) or both co-infections. One study from China also reported the mortality was higher in patients with triple infection or HCV-co-

*Corresponding author: Min Wei, School of Medicine, Nankai University, No.94 Weijin Road, Tianjin, China, Tel: 0086-022-23509579; E-mail: weimin@nankai.edu.cn

Received August 11, 2017; Accepted August 18, 2017; Published August 25 2017

Citation: Ma P, Qian J, Gao L, Zhang D, Yu A, et al. (2017) Management of Hepatotoxicity in HIV-Infected Patients Treated with Combined Antiretroviral Therapy (CART): A Retrospective Cohort Study in Tianjin, China. J AIDS Clin Res 8: 723. doi: 10.4172/2155-6113.1000723

Copyright: (c) $2017 \mathrm{Ma}$ P, et al. This is an open-access article distributed unde the terms of the Creative Commons Attribution License, which permits unrestricted use, distribution, and reproduction in any medium, provided the original author and source are credited. 
infection than those with mono-HIV-infection [3]. However, there is little research examining cART-related hepatotoxicity in the absence of HBV or HCV co-infection in HIV-infected individuals in China.

The first aim of this study was to estimate the risk of hepatotoxicity of cART in the absence of HBV or HCV co-infection in HIV-infected people, and to define other potential risk factors that may influence hepatotoxicity in this population. Secondly, we attempted to describe the effects of continuation or modification of the cART regimen according to the marker liver enzyme elevation (LEE) among these patients. Based on our results, we propose a feasible plan for the management of cARTrelated hepatotoxicity in such a population.

\section{Patients and Methods}

\section{Study population}

China maintains a network known as the National Free Antiretroviral Treatment Program database, which is established and managed by the National Center for AIDS/STD Control and Prevention, Chinese Center for Disease Control and Prevention (China CDC). We assessed all data from the database of The Tianjin Second People's Hospital, a branch of this network, from April 1, 2010 to March 31, 2016 (data downloaded on April 16, 2016). All available data were collected, including patients' medical records, age, gender, routes of transmission, prescribed initial and subsequent cART regimens.

HIV infection status was based on positive HIV screening ELISA tests from two peripheral blood samples and confirmed by western blot. HIV test sites were certified by the National AIDS Reference Laboratory at China CDC. A diagnosis of HCV was given to patients who were seropositive for HCV or positive for HCV RNA. HBV diagnosis was assigned to patients who were positive for hepatitis B surface antigen, hepatitis B E antigen, hepatitis B core antibodies, or HBV DNA during the study period. Patients with chronic HCV infections or chronic HBV infections were excluded from this study. Patients with unknown HBV or HCV status were also excluded. The lost patients during followup were not included in this study. Severe alcohol use was defined according to the WHO definition of alcohol consumption, which uses $>40 \mathrm{~g} / \mathrm{d}$ in females and $>60 \mathrm{~g} / \mathrm{d}$ in males as cut-off values. Patients who were older than 18 years, treatment-naive, and started a standard cART regimen containing two nucleoside and one non-nucleoside reversetranscriptase inhibitors (NRTIs and NNRTIs, respectively, which is called first line regimen) were eligible for this study. All patients in this study were treated naive, but not all were newly diagnosed.

Liver enzyme elevation (LEE) was defined as elevation of liver enzyme than normal values. In this study, the normal values of alanine transaminase (ALT) and aspartate transaminase (AST) are both $0 \sim 40$ $\mathrm{U} / \mathrm{L}$. The normal value of total bilirubin (TBIL) is $1.7 \sim 17.1 \mu \mathrm{mol} / \mathrm{L}$. According to Chinese National guideline of HIV/AIDS therapy, hepatotoxicity was also graded as 1, 2, 3 and 4 [12]. Grade 1 of hepatotoxicity was defined as ALT and/or AST and/or TBIL $<3$ times of upper limit of normal (ULN); Grade 2 was $\geq 3$ and $<5$ times of ULN; Grade 3 was $<10$ and $\geq 5$ times of ULN; Grade 4 was $\geq 10$ times ULN.

\section{Statistical analysis}

The data was input into the SPSS software and analyzed. To compare the difference before and after cART regimens, Student T test or nonparametric test- Wilcoxon test were applied accordingly.

\section{Role of the funding source}

The funder had no role in study design, data collection, data analysis, data interpretation, or writing of the report. The author had full access to all data used in the study and had final responsibility over the decision to submit for publication. Written informed consent was obtained from each patient included in the study and the study protocol conformed to the ethical guidelines of the 1975 Declaration of Helsinki as reflected in a priori approval by the institution's human research committee.

\section{Results}

\section{Demographic and clinical characteristics of enrolled patients}

We collected data for all patients enrolled from April 1, 2010 to March 31, 2016 in The Tianjin Second People's Hospital. Of total 2532 participants followed for 6 years, 115 patients (4.5\%) were HCV positive, 121 (4.8\%) were HBV positive, $14(0.06 \%)$ had triple infection and 12 patients $(0.05 \%)$ were $\mathrm{HBV}$ or $\mathrm{HCV}$ status unknown at the enrollment or during follow-up. The rest were all HBV and HCV negative (Figure 1). A total of $\mathrm{HBV}$ and $\mathrm{HCV}$ negative and HIV positive 2270 participants were included in this study and followed 13334.8 person-years. Among them, only 30 cases ( $1.3 \%$ or 2.2 per 1000 personyears) developed hepatotoxicity. Another 67 patients (3.0\% or 5.0 per 1000 person-years) died of non liver-related diseases. However, nobody died of liver-related diseases. Thus, the incidence of liver-related deaths in persons without $\mathrm{HCV}$ or HBV was zero percent during follow-up. The non-liver related diseases include Pneumocystsis carinii pneumonia (PCP), cryptococcal encephalitis, tuberculous meningitis, etc.

The characteristics of 30 patients who developed hepatotoxicity are listed in Table 1. Compared to 2240 patients who used the same cART regimens in the hospital, only these 30 cases developed hepatotoxicity. Our study focused on these 30 patients. The average age of these patients were 45 years (Table 1). Seventeen patients $(56.67 \%)$ became infected with HIV by homosexual contact, 7 patients $(23.33 \%)$ by heterosexual contact and 4 patients (13.33\%) by intravenous drug use (IDU).

LEE was observed in the majority of subjects $(60 \%)$ within 1 month of start of cART. After 1-3 months of cART, 7 (23.33\%) patients developed LEE (Table 1). The initial cART regimens are listed in Tables 1 and 2. Except cART hepatotoxicity, other reasons could also cause

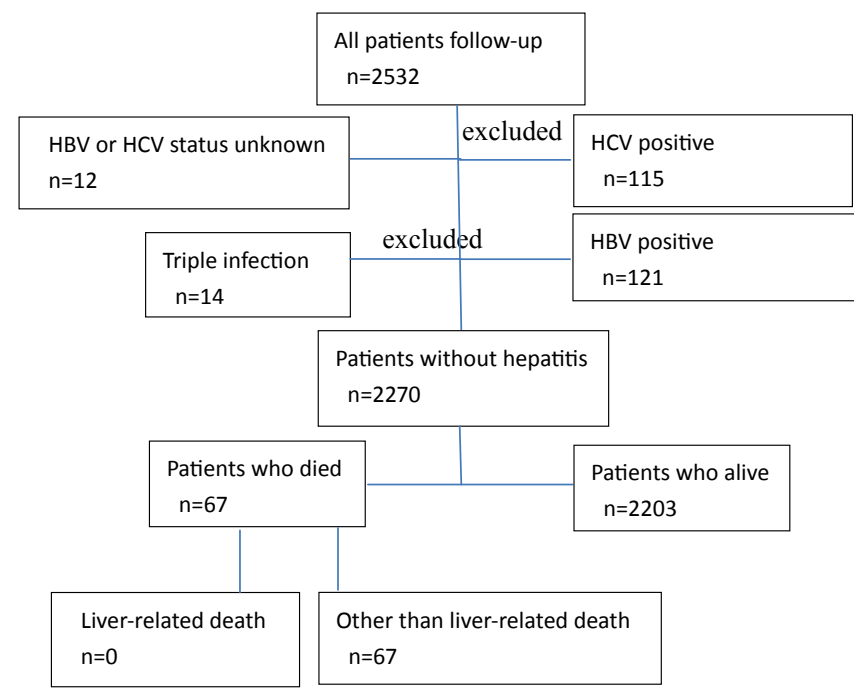

Abbreviations: HBV: Hepatitis B Virus; HCV: Hepatitis C Virus

Figure 1: Patient flowchart. 


\begin{tabular}{|c|c|c|}
\hline Variable & Value & $\%$ \\
\hline All & 30 & 100.00 \\
\hline \multicolumn{3}{|l|}{ Gender } \\
\hline Male & 30 & 100.00 \\
\hline \multicolumn{3}{|l|}{ Age (years) } \\
\hline $20-30$ & 5 & 16.67 \\
\hline $30-40$ & 6 & 20.00 \\
\hline $40-50$ & 9 & 30.00 \\
\hline $50-60$ & 8 & 26.67 \\
\hline $60-$ & 2 & 6.67 \\
\hline Age (mean \pm SD) & $43.53 \pm 12.11$ & \\
\hline \multicolumn{3}{|l|}{ Routes of transmission } \\
\hline Homosexual & 17 & 56.67 \\
\hline Heterosexual & 7 & 23.33 \\
\hline Intravenous drug use & 4 & 13.33 \\
\hline Unknown & 2 & 6.67 \\
\hline Years of follow up (mean \pm SD) & $2.95 \pm 1.60$ & \\
\hline \multicolumn{3}{|l|}{ Initial regimen } \\
\hline$E F V+3 T C+A Z T$ & 7 & 23.33 \\
\hline$E F V+3 T C+D 4 T$ & 3 & 10.00 \\
\hline$E F V+3 T C+T D F$ & 10 & 33.33 \\
\hline$N V P+3 T C+A Z T$ & 9 & 30.00 \\
\hline NVP+3TC+TDF & 1 & 3.33 \\
\hline CD4 (mean $\pm \mathrm{SD}$ ) cells $/ \mu \mathrm{L}$ & $203 \pm 133$ & \\
\hline ALT $($ mean $\pm \mathrm{SD}) \mathrm{U} / \mathrm{L}$ & $30.57 \pm 13.13$ & \\
\hline AST (mean \pm SD) U/L & $29.87 \pm 11.81$ & \\
\hline TBIL(mean $\pm S D) \mu \mathrm{mol} / \mathrm{L}$ & $15.40 \pm 15.44$ & \\
\hline \multicolumn{3}{|l|}{ LEE was observed after cART (months) } \\
\hline $0-1$ & 18 & 60.00 \\
\hline $1-3$ & 7 & 23.33 \\
\hline $3-6$ & 3 & 10.00 \\
\hline 6- & 2 & 6.67 \\
\hline $\begin{array}{l}\text { LEE was observed after cART (month, } \\
\text { mean } \pm \text { SD) }\end{array}$ & $3.6 \pm 7.5$ & \\
\hline
\end{tabular}

EFV: Efavirenz; 3TC: Lamivudine; AZT: Zidovudine; D4T: Stavudine; NVP: Nevirapine; TDF: Tenofovir; ALT: Alanine Transaminase; AST: Aspartate Transaminase; TBIL: Total Bilirubin; LEE: Liver Enzyme Elevation; cART: Combined Anti-Retroviral Therapy; SD: Standard Deviation

Table 1: Demographic and clinical characteristics of the patients with hepatotoxicity at baseline.

hepatotoxicity, such as alcohol abuse or fatty degeneration of liver. When hepatotoxicity reached grade 2 or more in these patients and we excluded other reasons, we changed their regimens (Table 2). In the initial regimens (first-line regimens), $66.67 \%$ patients used EFVcontaining regimens and $33.33 \%$ used NVP-containing regimens (Table 1). In the new regimens (second-line regimens), we replaced NVP or EFV with Lopinavir and Ritonavir tablets (LPV/r) in all cases.

\section{Comparison of liver function before and after the initial and new regimens}

Because LEE is a marker for hepatotoxicity, we monitored alanine transaminase (ALT), aspartate transaminase (AST) and total bilirubin (TBIL) respectively, before and after the initial cART regimens, and after the new regimens. Table 3 lists the results. Before beginning cART, values for ALT, AST and TBIL in most patients were normal or slightly higher than normal. After start of initial cART regimens, significant elevations of ALT and AST were observed, and a small increase in TBIL was found in most of these patients. When hepatotoxicity reached grade 2 or more in these patients and we excluded other reasons, we

\begin{tabular}{|c|c|c|c|}
\hline $\begin{array}{l}\text { Patient } \\
\text { Number }\end{array}$ & Initial Regimens & New Regimens & $\begin{array}{l}\text { LEE observed } \\
\text { (months) }\end{array}$ \\
\hline 1 & $E F V+3 T C+D 4 T$ & $\mathrm{LPV} / \mathrm{r}+3 \mathrm{TC}+\mathrm{TDF}$ & 4 \\
\hline 2 & $E F V+3 T C+D 4 T$ & $\mathrm{LPV} / \mathrm{r}+3 \mathrm{TC}+\mathrm{TDF}$ & 1 \\
\hline 3 & $\mathrm{NVP}+3 \mathrm{TC}+\mathrm{AZT}$ & $\mathrm{LPV} / \mathrm{r}+3 \mathrm{TC}+\mathrm{TDF}$ & 0.5 \\
\hline 4 & $\mathrm{NVP}+3 \mathrm{TC}+\mathrm{AZT}$ & $\mathrm{LPV} / \mathrm{r}+3 \mathrm{TC}+\mathrm{TDF}$ & 0.5 \\
\hline 5 & $E F V+3 T C+T D F$ & $\mathrm{LPV} / \mathrm{r}+3 \mathrm{TC}+\mathrm{TDF}$ & 1 \\
\hline 6 & $E F V+3 T C+T D F$ & $\mathrm{LPV} / \mathrm{r}+3 \mathrm{TC}+\mathrm{TDF}$ & 1 \\
\hline 7 & $E F V+3 T C+A Z T$ & $\mathrm{LPV} / \mathrm{r}+3 \mathrm{TC}+\mathrm{TDF}$ & 24 \\
\hline 8 & $N V P+3 T C+A Z T$ & $\mathrm{LPV} / \mathrm{r}+3 \mathrm{TC}+\mathrm{TDF}$ & 0.5 \\
\hline 9 & $E F V+3 T C+T D F$ & $\mathrm{LPV} / \mathrm{r}+3 \mathrm{TC}+\mathrm{TDF}$ & 1 \\
\hline 10 & $E F V+3 T C+T D F$ & $\mathrm{LPV} / \mathrm{r}+3 \mathrm{TC}+\mathrm{TDF}$ & 6 \\
\hline 11 & $\mathrm{NVP}+3 \mathrm{TC}+\mathrm{TDF}$ & $\mathrm{LPV} / \mathrm{r}+3 \mathrm{TC}+\mathrm{TDF}$ & 1 \\
\hline 12 & $E F V+3 T C+A Z T$ & $\mathrm{LPV} / \mathrm{r}+3 \mathrm{TC}+\mathrm{TDF}$ & 6 \\
\hline 13 & $E F V+3 T C+D 4 T$ & LPV/r+3TC+TDF & 36 \\
\hline 14 & $E F V+3 T C+A Z T$ & $\mathrm{LPV} / \mathrm{r}+3 \mathrm{TC}+\mathrm{TDF}$ & 1 \\
\hline 15 & $E F V+3 T C+T D F$ & $\mathrm{LPV} / \mathrm{r}+3 \mathrm{TC}+\mathrm{TDF}$ & 2 \\
\hline 16 & $\mathrm{NVP}+3 \mathrm{TC}+\mathrm{AZT}$ & $\mathrm{LPV} / \mathrm{r}+3 \mathrm{TC}+\mathrm{AZT}$ & 1 \\
\hline 17 & $\mathrm{NVP}+3 \mathrm{TC}+\mathrm{AZT}$ & $\mathrm{LPV} / \mathrm{r}+3 \mathrm{TC}+\mathrm{AZT}$ & 0.5 \\
\hline 18 & $N V P+3 T C+A Z T$ & $\mathrm{LPV} / \mathrm{r}+3 \mathrm{TC}+\mathrm{TDF}$ & 1 \\
\hline 19 & $E F V+3 T C+A Z T$ & LPV/r+3TC+TDF & 3 \\
\hline 20 & $N V P+3 T C+A Z T$ & $\mathrm{LPV} / \mathrm{r}+3 \mathrm{TC}+\mathrm{AZT}$ & 2 \\
\hline 21 & $E F V+3 T C+A Z T$ & LPV/r+3TC+TDF & 3 \\
\hline 22 & $E F V+3 T C+T D F$ & $\mathrm{LPV} / \mathrm{r}+3 \mathrm{TC}+\mathrm{TDF}$ & 0.5 \\
\hline 23 & $E F V+3 T C+T D F$ & $\mathrm{LPV} / \mathrm{r}+3 \mathrm{TC}+\mathrm{TDF}$ & 1 \\
\hline 24 & $E F V+3 T C+T D F$ & LPV/r+3TC+TDF & 2 \\
\hline 25 & NVP+3TC+AZT & LPV/r+3TC+TDF & 3 \\
\hline 26 & $E F V+3 T C+T D F$ & $\mathrm{LPV} / \mathrm{r}+3 \mathrm{TC}+\mathrm{TDF}$ & 1 \\
\hline 27 & $N V P+3 T C+A Z T$ & $\mathrm{LPV} / \mathrm{r}+3 \mathrm{TC}+\mathrm{TDF}$ & 0.5 \\
\hline 28 & $E F V+3 T C+A Z T$ & LPV/r+3TC+TDF & 1 \\
\hline 29 & $E F V+3 T C+A Z T$ & $\mathrm{LPV} / \mathrm{r}+3 \mathrm{TC}+\mathrm{TDF}$ & 2 \\
\hline 30 & $E F V+3 T C+T D F$ & $\mathrm{LPV} / \mathrm{r}+3 \mathrm{TC}+\mathrm{TDF}$ & 1 \\
\hline
\end{tabular}

LPV/r: Lopinavir+Ritonavir

Table 2: Initial and new regimens because of hepatotoxicity. changed their regimens. After the new regimens were applied, ALT, AST and TBIL values were continued to monitor after the first month, the second month and the sixth month. Within six months, the patients' ALT, AST and TBIL gradually returned back to normal levels. The values of ALT, AST and TBIL were also statistically compared. Liver function improved after one, two or six months of the application of new regimens, as shown in our statistical analyses (Table 4 and Figure 2). Thus, our data indicated that the new regimens containing LPV/r can alleviate the hepatotoxicity caused by EFV and NVP.

Notably, after the change of regimens and several months' of treatment on the new regimen, the patients' CD4+ cell counts significantly increased from 203 to 437 cells $/ \mu \mathrm{L}$ (Table 5). None of patients died from hepatotoxicity.

The mean level of ALT and AST was $191.37 \mathrm{U} / \mathrm{L}$ and 146.83 $\mathrm{U} / \mathrm{L}$, respectively after cART exposure, but returned to normal after switching to new regimens.

The mean level of TBIL was $25.41 \mu \mathrm{mol} / \mathrm{L}$. Values returned to normal two months after switching to new regimens.

\section{Discussion}

In this retrospective cohort study, $2270 \mathrm{HBV}, \mathrm{HCV}$ negative and HIV positive patients were followed for six years (13334.8 personyears). cART-related hepatotoxicity was well-controlled, and the 
Citation: Ma P, Qian J, Gao L, Zhang D, Yu A, et al. (2017) Management of Hepatotoxicity in HIV-Infected Patients Treated with Combined Antiretroviral Therapy (cART): A Retrospective Cohort Study in Tianjin, China. J AIDS Clin Res 8: 723. doi: 10.4172/2155-6113.1000723

Page 4 of 6

\begin{tabular}{|c|c|c|c|c|c|c|}
\hline & Grades & Baseline (\%) & LEE exposed (\%) & 1 month (\%) & 2 months (\%) & 6 months (\%) \\
\hline \multirow[t]{5}{*}{ ALT } & normal & $23(76.67)$ & & $12(40.00)$ & $12(40.00)$ & $21(70.00)$ \\
\hline & Grade 1 & $7(23.33)$ & $6(20.00)$ & $5(16.67)$ & $13(43.33)$ & $8(26.67)$ \\
\hline & Grade 2 & & $14(46.67)$ & $9(30.00)$ & $4(13.33)$ & $1(3.33)$ \\
\hline & Grade 3 & & $9(30.00)$ & $3(10.00)$ & $1(3.33)$ & \\
\hline & Grade 4 & & $1(3.33)$ & $1(3.33)$ & & \\
\hline \multirow[t]{5}{*}{ AST } & normal & $25(83.33)$ & $3(10.00)$ & $11(36.67)$ & $16(53.33)$ & $23(76.67)$ \\
\hline & Grade 1 & $5(16.67)$ & $15(50.00)$ & $12(40.00)$ & $13(43.33)$ & $7(23.33)$ \\
\hline & Grade 2 & & $5(16.67)$ & $5(16.67)$ & & \\
\hline & Grade 3 & & $5(16.67)$ & $1(3.33)$ & $1(3.33)$ & \\
\hline & Grade 4 & & $2(6.67)$ & $1(3.33)$ & & \\
\hline \multirow[t]{5}{*}{ TBIL } & normal & $23(76.67)$ & $16(53.33)$ & $11(36.67)$ & $15(50.00)$ & $18(60.00)$ \\
\hline & Grade 1 & $5(16.67)$ & $3(10.00)$ & $9(30.00)$ & $14(46.67)$ & $11(36.67)$ \\
\hline & Grade 2 & & $5(16.67)$ & $7(23.33)$ & $1(3.33)$ & $1(3.33)$ \\
\hline & Grade 3 & $1(3.33)$ & $6(20.00)$ & $3(10.00)$ & & \\
\hline & Grade 4 & $1(3.33)$ & & & & \\
\hline
\end{tabular}

Grade 1, $<3$ times upper limit of normal; Grade 2, $\geq 3$ and $<5$ times upper limit of normal; Grade 3, $<10$ and $\geq 5$ times upper limit of normal; Grade $4, \geq 10$ times upper limit of normal

$76 \%$ patients had normal ALT at baseline, $76 \%$ patients had grade $2-3$ LEE after CART exposure. And $70 \%$ patients returned to normal after switching to new regimens and liver protection

Table 3: ALT, AST and TBIL at baseline, at the time of elevation and 1, 2, 6 months of the application of new regimens (percent).

\begin{tabular}{|l|c|c|c|}
\hline & Time & Mean \pm SD & P value \\
\hline ALT & LEE exposed & $191.37 \pm 157.42$ \\
\hline & 1 months & $107.5 \pm 102.23$ & 0.000 \\
\hline & 2 months & $67.27 \pm 56.015$ & 0.014 \\
\hline AST & 6 months & $41.43 \pm 24.77$ & 0.000 \\
\hline & LEE exposed & $146.83 \pm 164.89$ & 0.000 \\
\hline TBIL & 1 month & $86.37 \pm 103.87$ & 0.05 \\
\hline & 2 months & $52.87 \pm 59.56$ & 0.217 \\
\hline & 6 months & $37.67 \pm 7.74$ & \\
\hline & LEE exposed & $25.41 \pm 20.89$ & \\
\hline
\end{tabular}

Table 4: Non-parametric test- Wilcoxon test.

\begin{tabular}{|l|c|c|c|}
\hline & $\begin{array}{c}\text { Baseline CD4 cell count } \\
(\mathbf{n = 3 0 )}\end{array}$ & $\begin{array}{c}\text { CD4 cell count after the treatment } \\
(\mathbf{n = 3 0 )}\end{array}$ & P (T test) \\
\hline Patients & $203 \pm 133 \mathrm{cells} / \mu \mathrm{L}$ & $437 \pm 207$ cells $/ \mu \mathrm{L}$ \\
\hline
\end{tabular}

Table 5: CD4 cell count before and after the cART treatment.

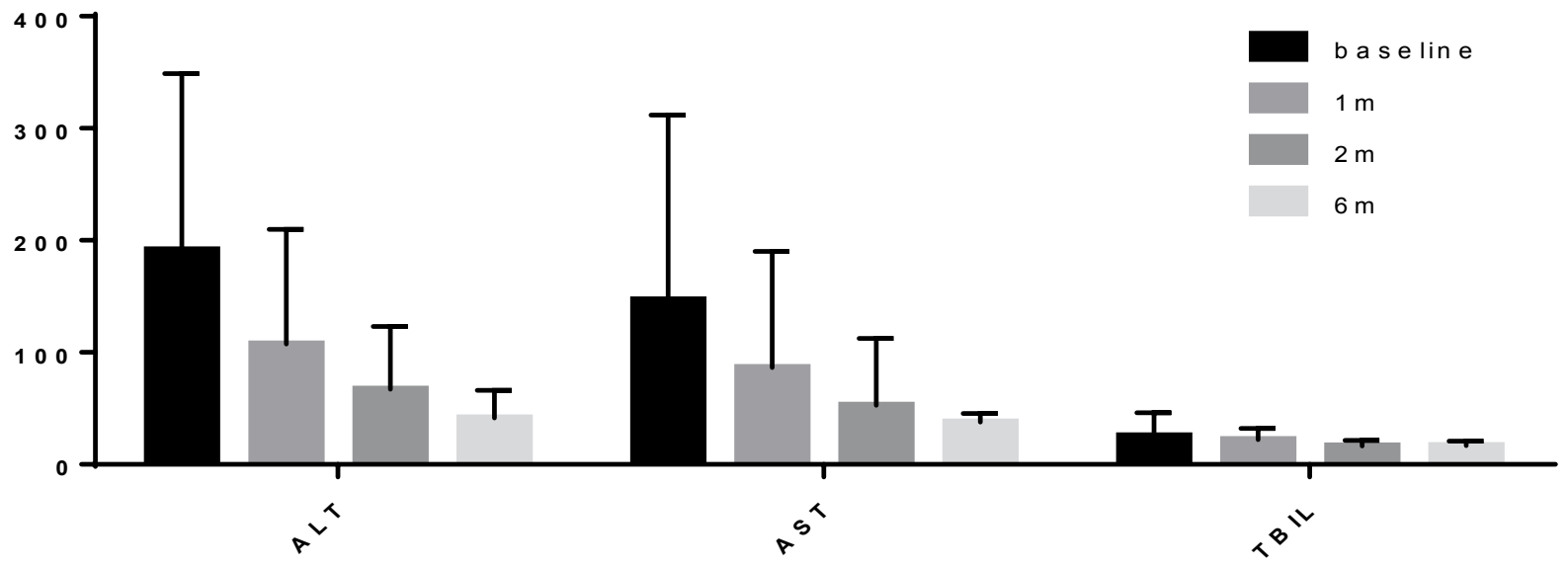

Figure 2: ALT, AST and TBIL at baseline, at the time of elevation and 1, 2, 6 months of the application of new regimens. 
Citation: Ma P, Qian J, Gao L, Zhang D, Yu A, et al. (2017) Management of Hepatotoxicity in HIV-Infected Patients Treated with Combined Antiretroviral Therapy (CART): A Retrospective Cohort Study in Tianjin, China. J AIDS Clin Res 8: 723. doi: 10.4172/2155-6113.1000723

Page 5 of 6

incidence of liver-related death was zero percent. 67 cases $(3.0 \%$ or 5.0 per 1000 person-years) died of non liver-related diseases, such as PCP, cryptococcal encephalitis etc. Of 2270 patients, only 30 cases $(1.3 \%$, or 2.2 per 1000 person-years) developed LEE, mostly as a consequence of cART-related hepatotoxicity. The cART regimens of these 30 cases contained EFV and NVP. These regimens were then replaced with LPV/r-containing regimens, and the patients' liver functions progressively improved over the subsequent 6 months. LEE was mainly observed during the first 3 months of initial treatment with EFV- or NVP-containing regimens. Due to increased risk of fatal events, cART should be stopped in patients with grade 3-4 hepatotoxicity. After observing LEE in the patients, we changed their regimens. No patients died during the follow-up of this study. This finding was very similar to the French Mortavic study in 2005, in which 48 of 287 deaths (17\%) in HIV-positive individuals were related to end-stage liver disease, and only 3 of 48 persons were HCV/HBV-negative $[6,9]$.

In HIV-positive patients without HCV- or HBV- co-infection, limited data was available on liver-related mortality. In the large population-based National Health and Nutrition Examination Survey (NHANES) III study in the United States, mortality of persons with chronic HCV infection was 4.4 (1.5-12.9) per 1000 person-years [13], but liver-related mortality in HCV-negative individuals was $0.16(95 \%$ CI, 0.10-0.25) per 1000 person years. Compared to the NHANES, our findings were zero percent among HIV-positive individuals without HCV or HBV co-infection. The reasons for this difference could be the limited cases in this study or well-managed cART regimens for the patients with high-grade hepatotoxicity.

Some studies showed that exposure to nucleoside reverse transcriptase inhibitors (NRTIs), particularly to the dideoxynucleosides (didanosine and zalcitabine), was related to the inhibition of mitochondrial DNA $\gamma$-polymerase, leading to severe hyperlactatemia and high mortality rate $[14,15]$. Thus, in China, these drugs are no longer recommended in the cART regimens.

Nonnucleoside reverse transcriptase inhibitors (NNRTIs) EFV and NVP, are widely used in China today, which can cause hepatotoxicity. Especially, NVP is associated with an increased risk of acute hepatotoxicity. According to national guideline [12], NVP is not used in patients with baseline CD 4 cell count $>250$ cells $/ \mu \mathrm{L}$. Wang J et al. [16] reported that hepatotoxicity was significantly associated with the median NVP trough concentrations among male patients, as well as HCV- co-infection. Our study was in agreement with these findings. We have observed gradual improvement in patients' liver function after replacing EFV or NVP with LPV/r.

In some reports, the prevalence of severe alcohol use in HIV positive individuals ranges from $2.8 \%$ to $35 \%$, depending on the observed population [17-20]. However, in this study, we didn't find any death related to alcoholic liver disease. We talked to the 30 patients who developed hepatotoxicity, and nobody reported severe alcohol use $(60 \mathrm{~g} / \mathrm{d})$. This could be the life style of these patients. We also found that many patients in this cohort were MSM patients. In Tianjin and other big cites in China, MSM patients are now becoming the main population infected with HIV. They usually have good educational background and are less at risk of alcohol abuse. However, this remains speculative because of the low number of patients and this need to be further investigated.

The strength of this study is the focus on population of hepatotoxicity without hepatitis virus co-infections in Tianjin, representing other big cities of China. Limitations are that we didn't report other cART-related side effects, which will be reported in other studies. In addition, patients totally lost in this cohort are unlikely to be on cART treatment. These missed cases are unlikely to contribute to rates of cART-related LEE.

\section{Conclusion}

In conclusion, this study provides evidence that cART-related hepatotoxicity can be controlled and managed by modifying the treatment regimens. Currently, the United States Food and Drug Administration (FDA) have approved more than 20 anti-HIV agents, and more options will likely be available in the future. In China, free cART only includes 8 therapeutic agents. Considering the risks and side effects associated with these medications, we hope that many HIVinfected patients in China will benefit from the future inclusion of additional agents in the free cART program.

\section{Lay Summary}

Hepatotoxicity caused by cART in HIV-infected patients should be monitored. Once liver function markers, such as alanine transaminase (ALT), aspartate transaminase (AST), are found higher than normal, the cART regimens should be changed accordingly to avoid the further hepatotoxicity and death to the patients.

\section{Acknowledgement}

We thank Professor Fusheng Wang, an academician of Chinese Academy of Sciences, for critically reading the manuscript. We also thank Dr. Cameron McKay for proofreading and Dr. Meiying Zhang for statistical analyses.

\section{Financial Support Statement} PM).

Science and Technology Foundation of Tianjin Health Bureau (2014KR03 to

\section{Author Contributions}

PM, JQ and LG designed the study and decided the therapeutic regimens. $D Z, A Y$ and $C Q$ performed the treatment to the patients and enter the data to the databank. PM and MW collected and analyzed the data. PM and MW wrote the paper

\section{References}

1. Shao Y (2006) AIDS epidemic at age 25 and control efforts in China Retrovirology 3: 87.

2. Wei M, Xing H, Feng Y, Hsi JH, Liu P, et al. (2015) Estimating HIV-1 transmission routes for patients with unknown risk histories by viral sequence phylogenetic analyses. J Acquir Immune Defic Syndr 70: 195-203.

3. Zhang F, Zhu H, Wu Y, Dou Z, Zhang Y, et al. (2014) HIV, hepatitis B virus and hepatitis $C$ virus co-infection in patients in the China national free antiretrovira treatment program, 2010-2012: A retrospective observational cohort study. Lancet Infect Dis 14: 1065-1072.

4. Zhang F, Dou Z, Ma Y, Zhang Y, Zhao Y, et al. (2011) Effect of earlier initiation of antiretroviral treatment and increased treatment coverage on HIV-related mortality in China: A national observational cohort study. Lancet Infect Dis 2011; 11: $516-524$

5. Notermans DW, van Leeuwen R, Lange JM (1996) Treatment of HIV infection: Tolerability of commonly used antiretroviral agents. Drug Safety 15: 176-187.

6. Sulkowski MS, Thomas DL, Mehta SH, Chaisson RE, Moore RD (2002) Hepatotoxicity associated with nevirapine or efavirenz-containing antiretroviral therapy: Role of hepatitis C and B infections. Hepatology 35: 182-189.

7. Weber R, Sabin CA, Friis-Moller N, Reiss P, El-Sadr WM, et al. (2006) Liverrelated deaths in persons infected with the human immunodeficiency virus: The D:A:D study. Arch Intern Med 166: 1632-1641.

8. Lewden C, May T, Rosenthal E, Burty C, Bonnet F, et al. (2008) Changes in causes of death among adults infected by HIV between 2000 and 2005 The "Mortalite 2000 and 2005" surveys (ANRS EN19 and Mortavic). J Acquir Immune Defic Syndr 48: 590-598.

9. Rosenthal E, Salmon-Ceron D, Lewden C, Bouteloup V, Pialoux G, et al. (2009) Liver-related deaths in HIV-infected patients between 1995 and 2005 in the French 
Citation: Ma P, Qian J, Gao L, Zhang D, Yu A, et al. (2017) Management of Hepatotoxicity in HIV-Infected Patients Treated with Combined Antiretroviral Therapy (cART): A Retrospective Cohort Study in Tianjin, China. J AIDS Clin Res 8: 723. doi: 10.4172/2155-6113.1000723

GERMIVIC joint study group network (Mortavic 2005 study in collaboration with the Mortalite 2005 survey, ANRS EN19). HIV Med 10: 282-289.

10. Data Collection on Adverse Events of Anti-HIV drugs (D:A:D) Study Group, Smith C, Sabin CA, Lundgren JD, Thiebaut R, et al. (2010) Factors associated with specific causes of death amongst HIV-positive individuals in the D:A:D Study. AIDS 24: 1537-1548

11. Mocroft A, Soriano V, Rockstroh J, Reiss P, Kirk O, et al. (2005) Is there evidence for an increase in the death rate from liver-related disease in patients with HIV? AIDS 19: 2117-2125.

12. Wang A, Wang F, Mao Q (2011) National Guideline for HIVIAIDS therapy. Chin $\mathrm{J}$ Clin Infect Dis 4: 321-330.

13. El-Kamary SS, Jhaveri R, Shardell MD (2011) All-cause, liver-related, and non-liver-related mortality among HCV-infected individuals in the general US population. Clin Infect Dis 53: 150-157.

14. Falco V, Rodriguez D, Ribera E, Martínez E, Miró JM, et al. (2002) Severe nucleoside-associated lactic acidosis in human immunodeficiency virusinfected patients: Report of 12 cases and review of the literature. Clin Infect Dis $34: 838-846$
15. Arenas-Pinto A, Grant A, Bhaskaran K, Copas A, Carr A, et al. (2011) Risk factors for fatality in HIV-infected patients with dideoxynucleoside-induced severe hyperlactataemia or lactic acidosis. Antivir Ther 16: 219-226.

16. Wang J, Kou H, Fu Q, Han Y, Qiu Z, et al. (2011) Nevirapine plasma concentrations are associated with virologic response and hepatotoxicity in Chinese patients with HIV infection. Plos ONE 6: e26739.

17. Chander G, Lau B, Moore RD (2006) Hazardous alcohol use: A risk factor for non-adherence and lack of suppression in HIV infection. J Acquir Immune Defic Syndr 43: 411-417.

18. Samet JH, Cheng DM, Libman H, Nunes DP, Alperen JK, et al. (2007) Alcohol consumption and HIV disease progression. J Acquir Immune Defic Syndr 46 194-199.

19. Conen A, Fehr J, Glass TR, Furrer H, Weber R, et al. (2009) Self-reported alcohol consumption and its association with adherence and outcome of antiretroviral therapy in the Swiss HIV cohort study. Antivir Ther 14: 349-357.

20. Kovari H, Sabin C, Ledergerber B, Ryom L, Worm SW, et al. (2013) Antiretroviral drug-related liver mortality among HIV-positive persons in the absence of hepatitis $B$ or $C$ virus coinfection: The data collection on adverse events of antiHIV drugs study. Clin Infect Dis 56: 870-879. 